\title{
Ortodoxia e Heterodoxia Monetária: a Questão da Neutralidade da Moeda
}

\author{
Monetary orthodoxy and heterodoxy: \\ the question of currency neutrality
}

MARIA DE LOURDES ROLLEMBERG MOLLO*,

RESUMO: O artigo revisa as controvérsias sobre a neutralidade / não neutralidade da moeda na História do Pensamento Econômico, estabelecendo critérios para a classificação da ortodoxia e da heterodoxia, especialmente no que diz respeito às questões monetárias. $\mathrm{O}$ artigo enfatiza a não neutralidade da moeda sob a perspectiva da teoria monetária marxista da inflação, enfatizando as diferenças da teoria monetarista da inflação.

Palavras-chave: Moeda; neutralidade da moeda; não neutralidade da moeda; ortodoxia monetária; heterodoxia monetária.

ABSTRACT: The paper reviews the controversies on the neutrality/non-neutrality of money in the History of Economic Thought establishing criteria for the classification of orthodoxy and heterodoxy, especially in what concerns monetary issues. The article emphasizes the non-neutrality of money on the perspective of the Marxian monetary theory of inflation, making its point on the differences of the Monetarist theory of inflation.

KEYWORDS: Currency; neutrality of money; non-neutrality of money; monetary orthodoxy; monetary heterodoxy.

JEL Classification: E4; E5; E11; E12; E40; E50.

Embora o debate sobre a neutralidade da moeda seja antigo, e tenha se observado, ao longo do tempo, grande sofisticação na forma de argumentar a respeito, este tema continua dividindo opiniões e sendo objeto de controvérsias,

\footnotetext{
* Professora do Departamento de Economia da Universidade de Brasília. Campus Universitário Darcy Ribeiro, Brasília/DF, Brasil. E-mail: mlmollo@unb.br. Submetido: abril 2003; aceito: outubro 2003.

1 Agradeço a Adriana Moreira Amado, Alfredo Saad Filho, Joaquim Pinto de Andrade, José Luiz Oreiro e dois pareceristas anônimos pelos comentários que permitiram melhorar uma versão preliminar deste texto, bem como a um parecerista anônimo de outro artigo sobre o tema cuja crítica, ao ser respondida, inspirou este trabalho. Agradeço também ao CNPq, por financiamento de pesquisa maior, da qual este trabalho é um dos frutos. A responsabilidade pelas ideias aqui discutidas é apenas da autora.
} 
constituindo-se em importante divisor das correntes econômicas. Em trabalhos anteriores desenvolvemos inclusive uma classificação em que o conceito de neutralidade da moeda é indicador importante da ortodoxia ou heterodoxia econômicas (Andrade, Mollo e Silva, 1998; Mollo, Silva e Torrance, 2001). Este trabalho busca um detalhamento maior de tal classificação, aprofundando algumas análises do mainstream e da heterodoxia econômica a este respeito, dentro de leitura e enfoque heterodoxos.

Ortodoxia e heterodoxia são termos sempre relativos, o que requer que justifiquemos previamente qualquer esquema de classificação. A nossa é feita sobre a aceitação ou negação da Teoria Quantitativa da Moeda e da Lei de Say, o que requer explicações que serão dadas no item 1 do trabalho, logo após esta introdução. Nele discutiremos a relação entre a Teoria Quantitativa da Moeda e a Lei de

Say. Em seguida, é preciso detalhar o papel da neutralidade da moeda na classificação mencionada, explorando os conceitos de neutralidade caros ao mainstream e aceitos pela ortodoxia monetária. É o que faremos no item 2, enquanto o item 3 é dedicado ao tema da não neutralidade da moeda, defendida pelos heterodoxos. O item 4 sumaria as conclusões obtidas nos itens anteriores, articulando-as.

\section{LEI DE SAY, TEORIA QUANTITATIVA DA MOEDA E ORTODOXIA E HETERODOXIA ECONÔMICAS}

A idéia explicitada pela Lei de Say em seu enunciado é a de que o mesmo processo de produção que cria os produtos (oferta) gera também rendas, ao pagar salários, lucros, juros, rendas fundiárias e aluguéis, rendas essas que serão responsáveis pela compra dos produtos (demanda). Assim, o resultado da Lei de Say é um resultado harmônico de equilíbrio de mercados em geral, sejam os mercados de produtos, de um lado, sejam os de fatores de produção, como trabalho, capital, terra e recursos naturais, do outro.

Esta idéia de funcionamento harmônico da atividade econômica vem dividindo economistas ao longo da História do Pensamento Econômico, e está estreitamente relacionada às suas concepções de moeda. É preciso que a moeda seja vista como algo não desejável por si mesma para que não haja vazamentos no fluxo circular de renda que garante a Lei de Say, ou seja, no fluxo de rendas pagas pelas empresas às famílias pelos fatores de produção, rendas com as quais as famílias compram os produtos das empresas. Em caso contrário, os vazamentos correspondentes à moeda retida deixam de comprar produtos, os quais passam a sobrar, conduzindo à queda da utilização dos fatores de produção. O resultado é a crise, ou a negação da Lei 
de Say, com superprodução ou produção invendável, de um lado, e desemprego, do outro.

Observe-se, assim, que a retenção de moeda, ao provocar interrupção no circuito de rendas, afeta negativamente a produção. Surge, pois, em decorrência da aceitação do entesouramento como algo passível de ocorrer, visões distintas sobre a neutralidade ou não neutralidade da moeda. Existem também visões distintas sobre endogeneidade e exogeneidade da moeda relacionadas ao entesouramento. A moeda é exógena quando a sua quantidade é determinada, em última análise, pelas autoridades monetárias, e endógena quando as autoridades não controlam esta quantidade porque a demanda de moeda, influenciada por pressões internas da economia, afeta a oferta da mesma de forma imprevisível. O entesouramento é uma das razões que dificultam tal controle, dada sua imprevisibilidade. Assim, quando se supõe o entesouramento, a moeda é necessariamente endógena. Há, contudo, uma noção de endogeneidade diferente na abordagem novo-clássica, em particular na sua versão dos ciclos reais, em que a moeda é endógena porque acomoda as necessidades dos ciclos. Mas tal endogeneidade, observe-se, não se relaciona com o entesouramento e, por isso, não implica abdicar da neutralidade da moeda.

De fato, os que aceitam a Lei de Say precisam rejeitar que o entesouramento seja racional. Com isso, o fluxo circular da renda não se rompe e a moeda não provoca problemas no funcionamento econômico. Ou seja, a moeda é neutra e é a neutralidade da moeda que impede que ela afete de forma danosa o equilíbrio garantido pela Lei de Say. A rejeição do entesouramento aparece nas concepções ortodoxas de mercados de fundos de empréstimos, quando a oferta de empréstimos é igualada à poupança, ou seja, toda a renda poupada é emprestada, o que elimina a possibilidade de entesourar.

Ao desconsiderar o entesouramento, a demanda de moeda passa a ser vista, sobretudo, para atender a motivos transacionais, e então é sempre estável ou previsível, dependendo da renda que, nestas abordagens, tende sempre à estabilidade.

É essa estabilidade da demanda que facilita o controle da oferta de moeda pelo Banco Central. Na versão novo-clássica dos ciclos reais, embora a moeda bancária seja vista como passivamente criada para atender à demanda, a razão desta também é transacional, uma vez que King e Plosser (1994) assumem que é a moeda bancária que responde aos ciclos de negócios, e que os bancos produzem serviços de transação como fator de produção, usando trabalho, capital e outside money também como fatores de produção (Blanchard e Fisher, 1996). Como a demanda de moeda para transação depende da renda que, nesses modelos, tende à estabilidade após os ciclos Pareto-eficientes, a demanda de moeda é estável e a moeda criada tende a acomodar a demanda e os ciclos. 
Nesse caso, a moeda é endógena mas é neutra, já que o que provoca os ciclos são fatores reais, a moeda apenas viabiliza-os. ${ }^{2}$

Os opositores da Lei de Say, ao contrário, afirmam que existem razões para o entesouramento, mesmo que o entesouramento seja algo necessário e inevitável, dado o papel da moeda na economia capitalista. Assim, aceitam a idéia de instabilidade da demanda de moeda e de dificuldade do Banco Central para controlar a quantidade de moeda de forma eficaz.

A não neutralidade da moeda pode ser explicada por meio do entesouramento ou por meio dos efeitos do crédito. O entesouramento pode explicar os efeitos da moeda sobre a economia real porque significa impossibilidade de venda de algumas mercadorias, restringindo a produção de quem não vendeu. O crédito afeta a produção real porque a potencializa. Tanto o entesouramento de moeda, quanto os efeitos dela sobre a economia real (sua não neutralidade) permitem a ruptura do fluxo circular de renda e conduzem à rejeição da Lei de Say.

Ora, observe-se que os pressupostos necessários para se aceitar a Lei de Say, de negação da função de meio de entesouramento da moeda, e de neutralidade da moeda são os mesmos requeridos pela Teoria Quantitativa da Moe$\mathrm{da}^{3}$. É a ausência de entesouramento que torna a demanda estável e, conseqüentemente, a velocidade de circulação da moeda estável ou previsível. É, por sua vez, a neutralidade da moeda que impede que variações da quantidade de moeda afetem a produção real, garantindo efeito proporcional sobre o nível geral de preços, ou seja, provocando inflação. Finalmente, é o Banco Central que, podendo controlar a quantidade de moeda por meio de compensações de movimentos na velocidade de sua circulação, ao não fazê-lo corretamente, provoca inflação.

Os que não aceitam a Teoria Quantitativa da Moeda negam estes pressupostos. Os efeitos permanentes da moeda sobre a produção real (não neutralidade da moeda) evitam o crescimento proporcional do nível geral de preços. A

2 Como observam Blanchard e Fischer (1996), “o estoque real de moeda parece Grange-causar o produto". Mas os autores observam que a "correlação entre moeda nominal e produto teria que ser explicada em parte por comportamento do estoque de moeda emitida pelo banco central (outside money)". Para esses autores, a abordagem dos ciclos reais mostra que a correlação entre moeda e produto reflete em parte a causalidade do produto para a moeda bancária (inside money). Daí, sua endogeneidade. Mas observam que dependendo da tecnologia ligando os dois tipos de moeda, "a abordagem pode implicar que o volume real de moeda bancária é mais ligado ao ciclo do que a moeda do banco central". (Blanchard e Fischer, 1996)

${ }^{3}$ De forma sumária podemos dizer que a Teoria Quantitativa da Moeda diz que dada a equação de trocas $\mathrm{MV}=\mathrm{Py}$, onde $\mathrm{M}$ = quantidade de moeda; $\mathrm{V}$ = velocidade de circulação da moeda; $\mathrm{P}$ = nível geral de preços e y = nível real do produto, como $\mathrm{V}$ é considerada estável ou previsível e não há efeito permanente de variações de $\mathrm{M}$ sobre y, então todo aumento de $\mathrm{M}$ reflete-se proporcionalmente em aumento de P. Ou seja, a inflação é provocada por aumento da quantidade de moeda, e é de responsabilidade do Banco Central já que ele é o responsável pela criação de moeda (M).4 
instabilidade da demanda de moeda, em virtude do entesouramento, torna instável a sua velocidade de circulação, ${ }^{4}$ que não pode ser conhecida pelo Banco Central para controlar a quantidade de moeda em circulação de forma eficaz. Incapaz de controlar a quantidade de moeda, o Banco Central não pode ser, por essa razão, acusado de responsável pela inflação. Além disso, os críticos da Teoria Quantitativa da Moeda, ao rejeitá-la, negam que a inflação tenha apenas causas monetárias.

Uma vez que a Lei de Say, tanto quanto a Teoria Quantitativa da Moeda, foi aceita de forma dominante pelos economistas desde o início da Ciência Econômica, e tendo em vista a afinidade dos supostos necessários para aceitá-las, elas são um marco teórico importante na definição de ortodoxia econômica e na separação entre ortodoxos e heterodoxos em economia. Não é por outra razão que a Lei de Say e a Teoria Quantitativa da Moeda foram motivo de discórdias seminais, como aquelas presentes nas controvérsias do século XIX entre os "bullionistas" e "antibullionistas" 5 e entre os partidários da Currency School e da Banking School (Viner, 1937), ou nas críticas feitas por Marx às posições de Ricardo (Marx, 1970 e 1976) e por Keynes à concepção dos neoclássicos (Keynes, 1983), que continuam sendo divisores das correntes econômicas atuais. Pode-se, neste sentido, dizer sucintamente que neoclássicos, novos-clássicos e novos-keynesianos aceitam a Lei de Say e a Teoria Quantitativa da Moeda, pertencendo, por isso, à chamada ortodoxia econômica. Os neoclássicos monetaristas, como Friedman, e os novos keynesianos, aceitam-na apenas a longo prazo, como veremos adiante, enquanto os novos-clássicos, em particular a versão dos ciclos reais, aceitam-na a curto prazo. ${ }^{6}$ Ao contrário, os pós-keynesianos e marxistas, ao rejeitarem terminantemente tanto a Lei de Say quanto a Teoria Quantitativa da Moeda em qualquer tempo, formam a heterodoxia.

Trabalhos recentes do mainstream (Neumayer, 1998, por exemplo) parecem negar a classificação aqui proposta, uma vez que encontram efeitos reais a longo prazo com base em argumentos que começam com mudança nas variáveis monetárias. Mostraremos, contudo, no próximo item, que a forma como esse autores articulam tais mudanças monetárias e os efeitos sobre a eco-

\footnotetext{
${ }^{4}$ Torna também instável o multiplicador monetário.

${ }^{5}$ Referência aos adeptos da conversibilidade em ouro (bullion) das moedas e a seus opositores.

6 Em alguns trabalhos a Teoria dos Ciclos Reais é mencionada como uma teoria diferente dos novosclássicos. Entretanto, tendo em vista que assume a necessidade de microfundamentos, a racionalidade das expectativas e a idéia de mercado regulador a curto prazo, que caracterizam os novosclássicos, estamos aqui, a exemplo do que faz Mankiw (1990), tratando-a como uma vertente deles, ou uma das áreas de pesquisa da teoria novo-clássica. Quanto aos novos-keynesianos, o que os distingue dos novos-clássicos é a percepção de que o poder regulador do mercado a curto prazo é comprometido pela rigidez de preços, já que concordam tanto com a necessidade de fundamentos microeconômicos da macroeconomia, quanto com as expectativas racionais. A longo prazo as duas teorias se confundem. Elas formam o chamado mainstream.
} 
nomia real reforçam, ao invés de negar, tal classificação. Essa idéia será exposta a partir de uma resenha da noção ortodoxa de neutralidade da moeda, a seguir.

\section{A POSIÇÃO DOMINANTE EM ECONOMIA: A MOEDA NEUTRA}

Como diz Patinkin, "neutralidade da moeda é uma expressão curta para a proposição básica da teoria quantitativa de que apenas o nível de preços em uma economia, e não o nível de seu produto real, é que é afetado pela quantidade de dinheiro que circula" (Patinkin, 1989, p. 273).

Ao longo dos debates econômicos esta definição recebe detalhamentos e complementações que tornam diferentes as posições de vários autores, mesmo dentro da ortodoxia monetária. Entre estas diferenças destacam-se as referentes ao prazo em que a neutralidade da moeda se impõe, ao grau da neutralidade e às razões desta neutralidade.

A aceitação da Teoria Quantitativa da Moeda, desde Hume (1752/1963) e Ricardo (1817/1982), exigia que se concebessem os aumentos da quantidade da moeda como não tendo efeitos permanentes sobre a economia real. Havia, porém, os que aceitavam a existência de efeitos transitórios de estímulos à indústria entre a entrada do dinheiro em circulação e o crescimento dos preços (Hume, 1752/1963), seja porque os preços dos insumos crescem, afetando o nível geral de preços apenas depois que as rendas nominais cresceram, seja porque os preços dos produtos crescem antes das rendas salariais, aumentando lucros e investimentos (Viner, 1937). A idéia é então a de que pode haver, ao menos transitoriamente, um efeito monetário sobre a produção real e que, aumentado, por exemplo, após uma impulsão monetária, impede, ao menos durante algum tempo, o crescimento do nível geral dos preços. Em qualquer caso, porém, no pensamento ortodoxo, a moeda torna-se neutra a longo prazo, sendo a economia real afetada de forma permanente apenas por fatores reais (preferências e tecnologia).

Para que os efeitos reais sejam neutralizados, cumpre papel destacado a idéia de que é a quantidade real de moeda - e não a nominal - que importa para a decisão dos agentes econômicos (Friedman, 1989). Quanto mais rápido isso for percebido (ausência de ilusão monetária, conforme Patinkin, 1956/1965, e de erros de expectativa, conforme Friedman, 1989 e Friedman e Schwartz, 1963), e quanto mais estável for a demanda de moeda, mais rápido os preços reagem aos aumentos de demanda até que o nível geral de preços aumente proporcionalmente ao aumento da quantidade de moeda. Além disso, como os efeitos sobre a economia real ocorrem por meio de variações dos preços relativos, aos quais a oferta e a demanda respondem, quanto mais eles forem flexíveis, como querem os novos-clássicos, em particular os dedicados aos ciclos reais 
dos negócios, maior é a facilidade para que os ajustes ocorram, mais rápido o nível geral de preços sobe e a moeda se torna neutra mais depressa. Se, todavia, existem imperfeições de mercado, como pensam os novos-keynesianos, estas conduzem à rigidez de preços, e as dificuldades de ajuste levam

à neutralidade da moeda apenas a longo prazo (Rotemberg, 1982; Mankiw, 1985; Akerlof e Yellen, 1985; Blanchard e Kiotaki, 1980).

Nas diferentes concepções ortodoxas a não neutralidade da moeda, ou seja, os efeitos da moeda sobre a economia real, quando ocorrem, são transitórios e devidos a divergências entre as variáveis esperadas e efetivas (Friedman e Schwartz, 1963; Friedman, 1989; Barro e Fisher, 1976) ou entre taxas bancárias nominais de juros e taxas de rentabilidade real do capital (Wicksell, 1906), ou taxas real e nominal de juros (Fisher, 1930), ou ainda no período de "surpresa" dos agentes econômicos, até que incorporem o crescimento do nível de preços nas suas expectativas (Barro e Gordon, 1983). Em qualquer caso, as variáveis reais (preferências e tecnologia que se refletem nos preços relativos) são as responsáveis pelos efeitos permanentes e as nominais (quantidade de moeda e preços e salários nominais) cumprem papel meramente transitório na análise. Daí a neutralidade garantida no curto ou no longo prazo.

É a aceitação da neutralidade que justifica a prioridade de controle dos preços sobre a garantia do crescimento econômico. Nestas concepções o mercado é o regulador mais eficiente e é preciso, por isso, garantir que os preços relativos não fiquem distorcidos por processos inflacionários. Além disso, como a moeda é neutra, o crescimento do produto não é percebido como muito comprometido. No máximo o será de forma transitória. ${ }^{7}$ É esta neutralidade, pois, ou a idéia de efeitos meramente transitórios da moeda sobre a economia real que torna mais fácil, para seus defensores, a proposição de controle monetário restritivo para redução da inflação, uma vez que os custos sociais envolvidos não tendem a ser encarados como elevados. ${ }^{8}$ Além das divergências sobre o prazo mais ou menos longo para a moeda tornar-se neutra, há divergências quanto ao grau de neutralidade, uma vez que, para alguns autores, a moeda, além de neutra, é superneutra, ou seja, a atividade real é imune, não apenas à variação da quantidade de moeda, mas à variação da inflação (Barro e Fisher, 1976).

\footnotetext{
7 Daí a aceitação da Lei de Say.

${ }^{8}$ É o caso, por exemplo, da afirmação de Alesina e Tabellini (1986) de que "apesar da perda no produto e no gasto público, a autoridade fiscal faria melhor tendo um Banco Central mais independente" (p. 621), apesar de afirmarem pouco antes que "quanto mais independente é um Banco Central (...), menores são produto, inflação e maior a carga tributária” (p. 620-621). A idéia de que o Banco Central independente só não é necessário quando as autoridades monetária e fiscal não são coordenadas (Alesina e Tabellini, 1987) mostra também a prioridade dada ao controle de preços. A descoordenação garante que não haja pressão da autoridade fiscal sobre a monetária, comprometendo o objetivo de controle de preços.
} 
Nas palavras de Patinkin (1989), “a moeda é dita superneutra se um aumento na sua taxa de expansão de steady state, e então na correspondente taxa de inflação, não afeta nenhuma das variáveis reais do sistema, com exceção dos saldos reais" (Patinkin, 1989, p. 279). É a perda de poder de compra dos saldos reais que reduz a demanda de moeda e impede que ela tenha efeitos reais. Para os economistas do mainstream, que acham que a moeda pode não ser neutra a curto prazo, a idéia é a de que as impulsões monetárias afetam a repartição da renda ou da riqueza, podendo modificar a estrutura da produção e a alocação de recursos e, assim, alterar preços relativos e quantidades. Porém os gastos provenientes da nova repartição de renda vão provocando aumentos de preços relativos, e aumentando conseqüentemente o nível geral de preços até que ele tenha crescido na proporção do aumento da quantidade de moeda. Neste momento, as quantidades afetadas inicialmente já retornaram aos níveis anteriores, e o nível geral de preços maior é só o que resta do processo.

Vemos aqui que o aumento da quantidade de moeda é capaz de aumentar gastos mas não a capacidade produtiva, ou então, quando a capacidade produtiva aumenta, ela não é capaz de atender integralmente os aumentos da demanda. Em caso contrário, o nível de preços não subiria proporcionalmente. Daí a associação entre o longo prazo e o pleno emprego dos fatores de produção, nas parábolas ortodoxas, em que a capacidade não pode aumentar.

Em todas as versões ortodoxas da teoria monetária, o que garante o equilíbrio final com a moeda neutra é um sistema de mercado eficiente e, quanto maior sua eficiência (preços flexíveis, informação perfeita, concorrência perfeita), mais facilmente esta neutralidade é obtida. Além disso, importa também a estabilidade da demanda de moeda para garantir facilmente a sua neutralidade. Quanto mais importante analiticamente for o motivo transação para demandar moeda, mais estável tende a ser concebida a demanda monetária, já que esta depende da renda que, para os ortodoxos, tende a ser estável a curto ou a longo prazo, o que é outra forma de observar a importância do mercado e de sua lógica para as conclusões sobre a neutralidade. ${ }^{9}$ É, pois, a percepção de mercados como mecanismos eficientes de regulação econômica que garante que as variações de preços relativos na economia agregada vão se compen-

\footnotetext{
9 Como vimos, a demanda de moeda dos teóricos dos ciclos reais, ao ser relacionada ao motivo transação, tende a se estabilizar ao final dos ciclos Pareto-eficientes, razão pela qual a moeda, apesar de endógena, pode ser neutra. Em versões mais recentes do mainstream (novos-clássicos e novoskeynesianos), a percepção empírica da instabilidade da demanda de moeda deu origem à proposição de metas inflacionárias como forma de gestão monetária. Tal percepção, porém, não é bem explicada teoricamente, sendo apenas uma sugestão pragmática para resolver uma constatação empírica, e a demanda de moeda continua não afetando a longo prazo a economia real. Daí porque nos modelos de Taylor (1980), os gastos nominais são determinados via equação quantitativa, e embora haja uma relação entre a variabilidade do produto e a variabilidade da inflação, supõe-se que não há relação entre a taxa de inflação e o nível de produto a longo prazo (Goodfriend e King, 1997).
} 
sar nos vários mercados de forma a garantir que o nível geral de preços cresça proporcionalmente à quantidade de moeda, ficando a produção real imune a tais variações no final do processo. Uma vez que o mercado é, nestas concepções, o mecanismo de regulação econômica por excelência, nada mais importante do que respeitar suas regras, impedindo que interferências consideradas espúrias (extra mercado), como as ações discricionárias do Estado, venham a interferir.

Assim, quanto maior a neutralidade concebida da moeda, e quanto mais rapidamente ela se impuser, maior tende a ser, dentro da ortodoxia, a defesa de regras no debate regras $\mathrm{x}$ discricionariedade. Estas podem variar desde a regra fixa de emissão monetária até a idéia de Banco Central independente para cumprir compromisso de "disciplina monetária”, em qualquer caso eliminando a discricionariedade da política (Kydland e Prescott, 1977; Barro e Gordon, 1983; Alesina e Tabellini, 1988 e Alesina e Summers, 1993 entre outros). Nestas concepções, a eliminação da discricionariedade corresponde à retirada dos poderes do governo e dos políticos em geral no que tange à moeda, dando ao mercado o lugar de destaque na regulação monetária. É o que se percebe, por exemplo, quando Kydland e Prescott (1977) observam que "um arranjo institucional possível é o Congresso legislar estabelecendo regras monetárias e fiscais a se tornarem efetivas apenas depois de dois anos". A perda do poder político com medidas como essa, como eles próprios afirmam em seguida, “tornariam a política discricionária impossível” (p. 487).

Esse tipo de raciocínio nos leva não apenas à classificação já analisada no item 1, de ortodoxia vinculada à aceitação da Lei de Say e da Teoria Quantitativa da Moeda, e então da sua neutralidade, mas, no interior desta classificação, estes argumentos nos levam a considerar mais ortodoxos os pensamentos quanto mais rápida e facilmente a neutralidade se impuser, sendo este o caso de defesa mais forte das regras em favor da discricionariedade via política econômica em geral e política monetária em particular.

Os trabalhos recentes do mainstream estão todos, neste sentido, dentro da chamada ortodoxia monetária: os novos-clássicos mais ortodoxos, em particular os teóricos dos ciclos reais, assumem um ajuste mais rápido do mercado e uma neutralidade maior da moeda, enquanto os novos-keynesianos, ao perceberem rigidez de preços e imperfeições, impedem o mercado de ajustar-se a curto prazo, e se colocam no polo mais fraco da ortodoxia.

Trabalhos recentes do mainstream, como os de Neumayer (1998), exploram a existência de efeitos reais de choques monetários mesmo a longo prazo, parecendo negar a classificação acima. Observe-se, porém, que a economia real é afetada no seu modelo porque

a variabilidade esperada das variáveis nominais é muito alta devido a sua dependência de choques de políticas futuras. Esses excessos de flutuações 
nos níveis de preços são socialmente custosos porque contaminam os pagamentos reais de contratos financeiros nominais, reduzindo sua habilidade de se proteger contra choques econômicos. Uniões monetárias e câmbio fixo podem ser vistos como isolando a moeda das políticas domésticas. (Neumayer, 1998, p. 247)

Ora, aqui, como o texto deixa claro e o nosso grifo destaca, as variações nominais afetam primeiro o nível geral de preços (daí porque "contaminam os pagamentos reais dos contratos financeiros nominais") e, então, são neutras inicialmente. Só depois que o nível geral de preços subiu, e porque subiu, é que as expectativas dos agentes e a economia real são afetadas. Trata-se, pois, havendo proporcionalidade de variação de quantidade de moeda e de variação do nível de preços, de um caso de neutralidade a curto prazo da moeda. O que se nega, neste tipo de argumento, é apenas a superneutralidade. É por isso, ou seja, por conceber a moeda como neutra, que o trabalho de Neumayer (1998) prega regras monetárias ao invés de discricionariedade, condizendo sem problemas com a classificação aqui proposta para a ortodoxia.

Este efeito sobre a economia real a partir de choques monetários que passam pela mudança do nível geral de preços não é novidade. Ele aparece nos mecanismos de transmissão ligados aos efeitos de saldos reais (Patinkin, 1956/1965), ao efeito riqueza em geral (Pigou, 1917), nas expectativas adaptativas (Friedman, 1989, e Friedman e Schwartz, 1963) e até nas explicações da curva de Phillips, na medida em que nela a redução do desemprego só ocorre com inflação, ou seja, depois que a impulsão monetária agiu sobre o nível geral de preços. E mais ainda com a concepção de "expectativas racionais" ${ }^{10}$ por meio da idéia de que "um encarregado da política econômica discricionário pode criar inflação surpresa, que pode reduzir o desemprego e aumentar a receita governamental". (Barro \& Gordon, p. 589) Em trabalho recente de Mankiw (2000), por exemplo, é analisada a relação entre inflação e desemprego como inexorável, porque se evidencia na prática, mas o autor chama a atenção para o caráter ainda misterioso desta relação, uma vez que falta ainda uma explicação convincente para ela. ${ }^{11}$ Neste artigo, Mankiw diz que se se aceita a visão de que a política monetária influencia variáveis reais como o desemprego, explicar tal fato permanece o maior desafio para os teóricos econômicos. A teoria padrão de equilíbrio geral não dá nenhum papel para a unidade de conta.

\footnotetext{
10 O termo está entre aspas para chamar a atenção para o fato de que a racionalidade, embora associada aqui apenas ao mainstream, e de certa forma apropriada por ele, é sempre um suposto de qualquer teoria. A diferença é que, nas demais teorias, um comportamento sempre racional pode conduzir a uma situação de desequilíbrio.

11 Após analisar os conflitos entre a teoria e a evidência empírica, Mankiw (2002, p. 24) conclui que "existe uma forma simples de conciliar a nova curva de Phillips keynesiana com os dados: expectativas adaptativas", o que é problemático, na sua visão, pelo abandono das expectativas racionais.
} 
No mundo, porém, mudanças no valor da unidade de conta (ou seja, inflação) parecem cumprir um papel importante na alocação de recursos. (p. 7)

Assim, o que afeta a economia real nessas explicações é a inflação vista como provocada pelo aumento da quantidade de moeda, como reza a Teoria Quantitativa.

Nestas explicações, além disso, o impacto das variações da quantidade de moeda é sobretudo na demanda, e não na oferta via ampliação da capacidade produtiva. Se o efeito fosse sobre a oferta não haveria razão a longo prazo para que o nível geral de preços subisse proporcionalmente ao aumento da quantidade da moeda. Como veremos no próximo item, esta é uma diferença importante no que se refere ao pensamento heterodoxo ao justificar a não neutralidade.

\section{A HETERODOXIA MONETÁRIA E A NÃO NEUTRALIDADE DA MOEDA}

A idéia de moeda não neutra, para os heterodoxos, relaciona-se com o papel que concebem para a moeda e o crédito, bem diferente do atribuído pelos ortodoxos. Enquanto para os ortodoxos a moeda é um véu e a concessão de crédito é uma transferência de fundos poupados para financiar o investimento, com os bancos funcionando como meros intermediários, para os heterodoxos, tanto marxistas quanto pós-keynesianos, a moeda é fundamental na conexão ou coordenação da economia ${ }^{12}$ e o crédito rompe a restrição orçamentária e tem um papel ativo, potencializando a produção.

Este tipo de concepção da moeda e do papel do crédito é responsável pela idéia de moeda não neutra nas duas vertentes aqui mencionadas da heterodoxia, e é esta percepção que impede a heterodoxia de aceitar que todo aumento da quantidade da moeda seja necessariamente inflacionário, embora haja diferenças, por vezes grandes, nas argumentações e conclusões dos dois grupos de autores a propósito do impacto monetário sobre a inflação.

Enquanto na concepção pós-keynesiana de inflação as causas são principalmente reais e não monetárias, havendo apenas uma acomodação da quantidade de moeda aos estímulos reais para o crescimento dos preços, na concepção marxista pode haver excesso de moeda relacionado com inflação, embora esta reação não seja necessária, nem negue a não neutralidade da moeda. Começando pelos marxistas, vejamos adiante o que define a não neutralidade da moeda e, então, o caráter heterodoxo destas concepções.

Para Marx, a moeda é responsável pela divisão social do trabalho que só se faz por meio dela e, neste sentido, numa economia capitalista produtora de

12 A coordenação, porém, não é, nem num caso nem noutro, harmônica, implicando conflitos, instabilidades e crises. 
mercadorias, articula etapas e processos de produção separados e insere socialmente as classes sociais por meio da venda da força de trabalho e da realização do lucro monetário.

Para os marxistas, o crédito potencializa a acumulação de capital ao permitir o aumento de ritmo e da escala da produção, ao reduzir custos de circulação e ao antecipar, sincronizando, tanto a etapa de produção quanto a de circulação, já que com o crédito não é mais necessário esperar a realização de lucros para financiar aumentos de capacidade, e já que também o consumo pode ser antecipado via crédito e, com ele, a realização de lucros. (Marx, 1974; Foley, 1986; Mollo, 1994)

A concepção marxista admite uma idéia monetária de inflação, a de inflação causada por moeda extra, mas esta, como veremos, é uma idéia bastante diferente da idéia monetarista de inflação, e implica ainda a não neutralidade da moeda. Esta concepção foi discutida por vários autores marxistas, destacando-se, para sua compreensão, os trabalhos de Aglietta (1979), De Brunhoff e Cartelier (1974), De Vroey (1984) e Lipietz (1983).

A idéia básica é a de que embora a moeda potencialize a produção, a forma como a moeda é criada e demandada não garante que as proporções de sua criação sejam exatamente as adequadas e necessárias ao atendimento da demanda. Além disso, é possível que a moeda se destine a setores cuja resposta em termos de aumento da capacidade produtiva não seja imediata ou não responda às necessidades de demanda, em vista da chamada "anarquia da produção", o que representa impacto inflacionário. A moeda pode, por exemplo, fluir para setores onde não há capacidade ociosa ou onde os mercados estiverem saturados (De Vroey, 1984), ou ainda pode não provocar aumento suficiente ou suficientemente rápido da capacidade produtiva que, aumentando a produção, permita a formação de rendas efetivas necessárias ao cancelamento de dívidas referentes à criação de moeda, ou produção que compense o poder de compra adicional criado (Mollo e Saad Filho, 2001 e Saad Filho e Mollo, 2000). A possibilidade de crescimento dos preços a partir de um aumento de moeda que eleve a demanda está nos limites para o crescimento da oferta, como lembra Shaikh (1999): "se por qualquer razão o hiato entre a taxa de crescimento efetiva e os limites produtivos se estreita, haverá menos e menos espaço para o crescimento do produto e, conseqüentemente mais e mais pressão sobre os preços. A taxa de acumulação até o limite produtivo que chamo de coeficiente produtivo é então um índice de pressão inflacionária”. (p. 99)

Segundo este tipo de concepção, quando as mercadorias circulam, ou se trocam por dinheiro, na venda, convertem-se trabalhos privados em trabalho social, o que implica ver a moeda como representante social do trabalho (De Brunhoff, 1979; Mollo, 1991). O processo de criação monetária, porém, é um processo de criação de dívidas privadas ou públicas que, de imediato, ao serem criadas, não cumprem o papel social que a moeda tem que ter e, por isso, não 
socializam de per se a produção privada, ou o conteúdo de trabalho privado contido nas mercadorias. Para que isso ocorra de forma final ou definitiva, é preciso uma sansão social que envolva uma hierarquia de moedas criadas e sancionadas na sociedade como um todo. (De Brunhoff, 1974; Lipietz, 1983)

As dívidas, correspondentes à criação monetária pelos bancos, são o reconhecimento prévio de que em algum tempo posterior o tomador de créditos conseguirá cancelá-las com o que obtiver de renda no processo produtivo, ou como lucro ou como salário. Uma vez feito isso estará socializado o trabalho privado dos que elaboraram a mercadoria vendida a crédito. As decisões de emissão de dívidas que circulam permitindo a socialização dos trabalhos privados são tanto privadas (dos bancos que concedem crédito) quanto públicas (das autoridades monetárias que sancionam os créditos privados via emissão monetária e concessão de crédito aos bancos), e em nenhum caso há a onisciência do que ocorre nas várias unidades e processos produtivos de forma a bem avaliar o conteúdo de trabalho a socializar, ou de rendas a gerar para permitir o cancelamento final das dívidas. Assim, tanto a criação privada da moeda quanto a pública podem ser excessivas, se não proporcionarem aumento da produção e/ou da capacidade produtiva suficiente para gerar rendas que permitam compensar as dívidas correspondentes à criação monetária privada. No caso do não cancelamento destas dívidas há dois tipos de possibilidades. Ou as falências privadas conduzem à redução do poder de compra excessivo decorrente da criação da moeda extra e a inflação é evitada, ou a autoridade monetária sanciona tal poder de compra excessivo e a inflação decorrente é a forma da socializar perdas. A moeda extra corresponde então ao gasto de renda sem correspondência em formação da mesma no processo produtivo. (De Vroey, 1984)

Outra relação da moeda extra com a inflação é o caráter permissivo da primeira: sem moeda para viabilizar aumento de demanda não proporcional à oferta não há como os preços subirem.

A idéia de moeda extra aqui exposta distingue-se da ortodoxa porque, em primeiro lugar, não há uma concepção de pleno emprego nem a curto nem a longo prazo, o que abre a possibilidade não apenas de aumento de produção, mas de aumento da capacidade produtiva. Em segundo lugar, a moeda pode ou não afetar a produção, afetando em maior ou menor medida os diferentes setores, o que altera os preços relativos (economia real) necessariamente, não sendo, portanto, neutra. Além disso, nesse tipo de concepção monetária, a formação do valor é um processo que se verifica tanto na produção, pelo conteúdo de trabalho necessário à produção das mercadorias, quanto na circulação, onde é determinado de forma final o trabalho socialmente necessário ou as condições sociais médias de produção por meio de um "tateamento social" quando as mercadorias se confrontam umas com as outras (De Brunhoff, 1973 e 1974). Assim, quando o Banco Central sanciona a criação privada de moeda, está sujeito a sancionar preços e rendas decorrentes deles no processo de circu- 
lação, que são expressões imperfeitas dos valores, estes últimos responsáveis pela formação das rendas no processo de produção (De Brunhoff 1973; De Brunhoff e Cartelier, 1974; Mollo e Saad Filho, 2001). Tais divergências ou incompatibilidades entre produção e circulação afetam diferentemente os vários setores, e são fontes de crises (Mollo, 1989), o que é outra forma de analisar a não neutralidade da moeda. Em terceiro lugar, a moeda é endógena (Mollo, 1999), criada pelos bancos e autoridade monetárias, e a criação da moeda extra e a possível inflação não são, pois, de responsabilidade apenas do Banco Central, como quer a ortodoxia.

Uma forma de visualizar melhor a diferença entre as duas concepções monetárias de inflação é observar que, como a criação nova de moeda pode provocar inflação mas não necessariamente o faz, é provável que a moeda extra, ao fluir para setores cuja produção não responda de imediato com aumento de produção e/ou capacidade produtiva, forneça impulso para o crescimento dos preços no curto prazo, mas ao fluir e afetar de forma diferenciada os vários setores e então os preços relativos, afeta a médio e longo prazo a produção agregada, o que pode impedir a longo prazo o crescimento do nível geral de preços. Assim, ao contrário do que ocorre com o pensamento ortodoxo, é de se esperar que os efeitos da moeda sobre a economia real (não neutralidade) sejam maiores e mais gerais a longo prazo e não a curto.

Observe-se aqui que a concepção ortodoxa de moeda é sobretudo de demanda como meio de transação que tende a se espalhar pelos diversos setores da economia, em raciocínio do tipo do de vasos comunicantes. Para onde há produção disponível a moeda flui e, como não afeta a produção propriamente dita de forma permanente, os preços vão subindo à medida que a produção escasseia, até que os níveis gerais de preços se elevem proporcionalmente ao novo poder de compra criado. Para a concepção marxista, todavia, à medida que a moeda vai sendo criada, tem um impacto maior ou menor nos vários setores, o que altera os preços relativos sem que tal alteração garanta que o nível geral de preços esteja sempre subindo. Isto porque, por um lado, nem toda moeda criada é gasta já que pode, por exemplo, ser retida como meio de entesouramento. ${ }^{13}$ Por outro, nem todo gasto amplia preços, porque tanto a produção quanto a capacidade de produção podem aumentar. Finalmente, e isso é melhor explicado pela heterodoxia pós-keynesiana, o que ocorre em termos de ampliação da capacidade produtiva a curto prazo modifica irreversivelmente a estrutura econômica, impedindo a longo prazo a neutralidade da moeda.

Enquanto para os ortodoxos a inflação é sempre de demanda (por aumento de poder de compra com o aumento de moeda), para os pós-keynesianos os

\footnotetext{
13 Parte da moeda pode, também, vazar do sistema produtivo em questão sob a forma de importações, e pode haver ainda destruição de moeda em pagamentos de dívidas superiores à produção que lhes deu origem.
} 
problemas estão sobretudo do lado da oferta, via aumentos de custos, embora para Keynes e alguns pós-keynesianos possa haver inflação de demanda quando a economia se aproxima do pleno emprego.

Para os que assumem que a moeda apenas acomoda movimentos anteriores dos preços, a idéia é a de que na equação de trocas $M V=$ Py a causalidade vai de Py para MV, na medida em que a renda nominal Py é financiada por aumentos de empréstimos, o que leva residualmente a aumentos de $\mathrm{M}$ no outro lado dos balanços bancários (Smithin, 1994). A inflação então precede o aumento de moeda, sendo provocada por aumento de custos, em particular salários. (Moore, 1988; Kaldor, 1986; Laidler, 1989)

Para os pós-keynesianos "qualquer aumento de preço é um aumento na renda de alguém”, e então "inflação é [...] um sintoma de luta pela distribuição da renda" (Davidson, 1991, p. 88 e 89) ${ }^{14}$. Por outro lado, com o sistema econômico e o sistema financeiro atuais, observa-se permanente poder de grupos econômicos que impedem concorrência perfeita e garantem pressão inflacionária permanente, requerendo, para combatê-la, políticas de rendas. Visto dessa maneira, o processo inflacionário é fruto de fatores reais, embora Keynes e os pós-keynesianos reconheçam que o sistema bancário pode fornecer a liquidez necessária aos empresários para que eles, aumentando salários nominais e custo das matérias-primas sancionem a inflação. Reconhecem, todavia, que a política ortodoxa de contenção monetária pode reduzir a inflação mas, ao mesmo tempo, como a moeda não é neutra, produz uma massa enorme de desempregados.

Ao tratar dos aumentos de custos que provocam inflação, os pós-keynesianos se referem, além dos aumentos salariais, a aumentos das margens de lucro, rendimentos decrescentes, custos dos produtos importados e choques de oferta. A inflação pode também ser de demanda, mas esse é um caso menos provável porque só ocorre após o pleno emprego. (Sicsú, 2003 e Davidson, 1991)15

Para Keynes, em particular nos trabalhos a partir da Teoria geral (1936), e para os pós-keynesianos, a moeda é garantia contra incerteza que permeia a economia por ser o ativo mais líquido, e nesse sentido influencia decisões importantes dos agentes econômicos. As principais decisões, em particular o in-

\footnotetext{
14 Também para os marxistas o conflito distributivo é uma causa da inflação embora, para eles, ele se inicie sobretudo do lado do capital, com aumentos de lucros e não de salários, como em algumas versões teóricas pós-keynesianas.

15 Para tratar as inflações de custo os pós-keynesianos não aceitam aumentos da taxa de juros ou contenção monetária que inibem o investimento e ampliam o desemprego, mas sugerem medidas de redução de custos como a TIP (tax based on income policy), punindo empresas que sancionem aumentos salariais ou de lucros acima do permitido por ganhos de produtividade; redução de impostos que venham a reduzir custos; políticas cambiais, tributárias, monetárias e industriais direcionadas para a redução de custos de importações; e estoques reguladores para reduzir o impacto de choques de oferta. (Sicsú, 2003).
} 
vestimento, implicam uma articulação complexa entre passado, presente e futuro, via decisões baseadas em expectativas incertas e resultados de decisões presentes que afetam irreversivelmente o futuro. É a moeda que articula no tempo tais decisões e resultados, num contexto de tempo histórico, diferentemente do tempo lógico dos ortodoxos.

Dado o caráter incerto do mundo, "a mecânica celestial da teoria de equilíbrio neoclássico, onde todas as ações individuais são pré-conciliadas dentro de uma coerência racional, torna-se irrelevante" (Rousseas, 1986, p. 18), e a moeda passa a ser fundamental como forma de conviver com tal incerteza, via contratos monetários. Os contratos monetários articulam decisões ex-ante com resultados ex-post no nível privado, que "transformam a incerteza em relativa certeza” (Rousseas, 1986, p. 20). Como a incerteza não é toda eliminada, porque decorre da descentralização das decisões e do futuro desconhecido, os agentes econômicos agem baseados em expectativas sempre subjetivas, sujeitos a erros, e são essas expectativas subjetivas que conduzem à volatilidade do investimento e à instabilidade do capitalismo como norma. Em momentos de incerteza e de baixo grau de confiança nas expectativas, a decisão de investir é comprometida porque as pessoas preferem a liquidez da moeda, retendo-a, o que inibe o investimento e, via efeito multiplicador, restringe ainda mais o crescimento da renda e do emprego. Essa é a fonte da não neutralidade da moeda para Keynes e os pós-keynesianos.

No que se refere ao papel potencializador sobre a produção que o crédito tem, é por meio do motivo finança que se observa melhor a posição de Keynes e dos póskeynesianos. O crédito, ao contrário do que pensam os ortodoxos, não requer poupança prévia. Os bancos concedem créditos rotativos que atendem à demanda de financiamento, viabilizam e concretizam a decisão de investir (Keynes, 1983; Minsky, 1982; Studart, 1999). O impacto do investimento, ao aumentar a renda via efeito multiplicador, por sua vez, é que vai garantir que ex-post a poupança se iguale ao investimento, não tendo sido ex-ante necessária para financiá-lo. O papel da poupança, neste tipo de análise, é apenas o de fundar o investimento a posteriori, ou seja, dentro de um mercado financeiro desenvolvido, permitir, pela quantidade e qualidades de produtos financeiros diferenciados, a conversão de dívidas de curto prazo, relacionadas ao motivo finança, em dívidas de prazos mais longos, compatíveis com os de maturação dos investimentos feitos.

Assim, a não neutralidade da moeda é explorada quando se analisa o impacto da concessão de liquidez pelo sistema bancário na transição de uma escala de produção mais baixa para uma mais alta; assim como quando a preferência pela liquidez é analisada na contenção do crescimento e no desencadeamento das crises, conforme vimos anteriormente. No que se refere ao chamado motivo finança, Keynes mostra a importância do papel do siste- 
ma bancário, enfatizando por aí a não neutralidade da moeda criada por ele. Para ele,

Os bancos têm uma posição chave na transição de uma escala de atividade menor para uma maior. Se eles se recusam a relaxar a crescente congestão no mercado de empréstimos de curto prazo ou o mercado de novas emissões, como pode ser o caso, inibirão a melhoria, independente de quão frugal seja o propósito do público quanto a suas rendas futuras. (Keynes, 1983, p. 222)

A diferença aqui, com relação à moeda considerada endógena pelos teóricos dos ciclos reais, é que é a preferência pela liquidez dos bancos que pode provocar problemas, não sendo então neutra, enquanto na visão novo-clássica os bancos passivamente respondem à demanda de moeda provocada por fatores reais.

Minsky (1982) desenvolve esta idéia nos trabalhos sobre instabilidade financeira. A preocupação básica para ele, como para os pós-keynesianos em geral, não é o efeito que a expansão monetária possa ter para a inflação, mas o efeito negativo que a preferência pela liquidez dos bancos pode ter no processo de investimento e nas crises financeiras. Para Minsky, há uma tendência na economia capitalista a endividar-se mais em épocas de crescimento fluindo sem problemas. Entretanto, quando as perspectivas do sistema bancário credor mudam, e reduz-se seu otimismo diante do crescimento futuro, a preferência pela liquidez dos bancos os leva a restringir o crédito e isso pode transformar uma crise de liquidez em crise de insolvência generalizada. Para evitar tais crises, o Banco Central precisa ter um papel ativo de emprestador em última instância, emitindo e emprestando ao sistema bancário para evitar o crescimento da taxa de juros. É este crescimento que transforma unidades hedge ${ }^{16}$ em unidades especulativas, e unidades especulativas em unidades Ponzi, fragilizando financeiramente a economia. Só o Banco Central, nessas condições, pode abortar crises, porque emite a moeda que atende aos diferentes graus de preferência pela liquidez. Esta é outra forma de ver a não neutralidade da moeda.

Esta não neutralidade é afirmada ainda na analise pós-keynesiana mencionada anteriormente pela concepção de tempo histórico, uma vez que, nesta visão, as mudanças observadas na produção e, sobretudo, na capacidade produtiva, como decorrência da concretização das decisões de investir, alteram

\footnotetext{
${ }^{16}$ Para Minsky as unidades produtivas podem ser classificadas quanto ao grau de prudência do endividamento. As unidades hedge são aquelas em que em todos os períodos significativos as receitas cobrem as saídas de recursos em pagamento de empréstimos tomados. As unidades especulativas são aquelas em que em alguns períodos significativos as receitas podem não cobrir as saídas para pagamento de empréstimos, mas as unidades empresariais podem se refinanciar. As unidades Ponzi são aquelas em que em todos os períodos significativos as saídas de recursos para pagar empréstimos são maiores do que as receitas. (Mollo, 1988).
} 
irreversivelmente a estrutura produtiva a longo prazo, impedindo que se possa conceber a não neutralidade a curto prazo e a neutralidade a longo prazo, já que este último nada mais é do que uma sucessão de curtos prazos. As mudanças estruturais provenientes do investimento impedem que os processos de ajustamento via mudanças de preços relativos sejam tais que mudanças produtivas em alguns setores sejam neutralizadas e os preços cresçam de forma a garantir o aumento do nível geral de preços a longo prazo, como quer a ortodoxia.

\section{CONCLUSÕES}

Da exposição anterior é possível perceber que a noção de neutralidade da moeda relaciona-se estreitamente com as conclusões de apoio à Lei de Say e à Teoria Quantitativa da Moeda, dois resultados fundamentais da teoria econômica, o que torna tal noção adequada para traçar a linha divisória entre ortodoxia e heterodoxia econômicas e mais particularmente entre ortodoxia monetária, que defende tais idéias, e heterodoxia monetária, que nega-as, criticando tanto a neutralidade da moeda quanto a Lei de Say e a Teoria Quantitativa.

A análise mais detalhada da noção de neutralidade permite classificar autores da própria ortodoxia e da própria heterodoxia, quanto ao grau em que ela se apresenta e às conclusões correspondentes de política monetária.

Assim, é possível ver reduzido o grau de ortodoxia quando os teóricos ortodoxos admitem flutuações reais provocadas por impulsões monetárias no curto prazo, embora a longo prazo a moeda continue sendo neutra. Neste sentido, mesmo quando os autores do mainstream admitem efeitos de longo prazo decorrentes de impulsão monetária, é preciso acompanhar o processo de transmissão para perceber que estes efeitos passam primeiro necessariamente pela variação do nível geral de preços, e só depois afetam o comportamento dos agentes interferindo sobre as variáveis reais, o que significa a aceitação (até a curto prazo) da Teoria Quantitativa da Moeda. Isto afirma, ao invés de negar, a neutralidade da moeda e, então, o caráter ortodoxo deste tipo de pensamento.

Por sua vez, é possível ver maior heterodoxia em autores como os pós-keynesianos, quando negam qualquer efeito inflacionário de impulsões monetárias, porque neste caso a não neutralidade da moeda é mais ampla.

O que conduz à idéia de não neutralidade da moeda tanto no curto quanto no longo prazo é que a moeda pode afetar não apenas a produção, mas a capacidade produtiva em alguns setores, mudando de forma permanente preços relativos e então afetando a produção real. Assim, mesmo no caso marxista que concebe alguns efeitos de criação monetária sobre o nível geral de preços, eles podem ocorrer a curto prazo em alguns setores e não em outros, o que, ao afetar preços relativos, conduz necessariamente à não neutralidade da moeda a longo prazo. 
A forma como a neutralidade é concebida implica conclusões distintas sobre a política monetária. Quanto mais ortodoxo é o pensamento a esse respeito, menos permanentes ou mais fugazes são os efeitos monetários sobre a economia real, e menores os custos sociais envolvidos, por exemplo, quando se restringe a quantidade de moeda. Por outro lado, mais rápido e danoso é o impacto atribuído por estes autores da variação monetária sobre o nível geral de preços, o que é particularmente problemático para eles porque o mercado, ou o sistema de preços que o rege, é o regulador econômico cosiderado mais eficiente, devendo ser defendido a qualquer custo. Neste caso, o Banco Central deve ter como único ou principal objetivo a defesa da estabilidade de preços, e o controle sobre a emissão monetária deve ser defendido até de pressões sobre a presidência do Banco Central (Friedman, 1971). Neste sentido, apesar de Friedman (1971) insistir que não quer o Banco Central independente, sua proposta é a do tipo maior de independência, o da regra fixa de emissão, capaz de tornar o controle monetário independente tanto dos interesses do Governo, quanto da direção do Banco Central, quanto dos bancos privados.

Os autores que admitem efeitos transitórios da moeda sobre a economia real admitem algum grau de discricionariedade na política monetária, seja para reduzir os custos sociais encontrados na contenção monetária na transição para o longo prazo, seja para compensar a rigidez de preços que impede o mercado de regular no curto prazo. O tipo de independência admitido para o Banco Central é o que implica alguma intervenção discricionária desde que mantida a prioridade do objetivo de estabilidade de preços a médio e longo prazos. O sistema de target-inflation, que estabelece metas de taxas de inflação sob controle admitindo algum crescimento, é o ideal para este tipo de decisão.

Para os heterodoxos, porém, o custo social envolvido no controle da quantidade de moeda pode ser grande e permanente, dada a não neutralidade da moeda. Assim, além de serem céticos com relação a este controle, em vista das suas concepções de moeda endógena (Mollo, 1999), a interferência na dinâmica monetária precisa ser extremamente cuidadosa para não se tornar indesejável.

Além disso, tanto na versão marxista da heterodoxia quanto na pós-keynesiana, a percepção da dinâmica monetária pelas autoridades monetárias é imprecisa e a própria dinâmica se altera todo o tempo, tornando sua apreensão problemática. No caso dos marxistas, isso se deve a uma concepção da moeda como relação social que envolve a sociedade como um todo, no qual a demanda de moeda compromete a oferta, e esta é tanto privada como pública. Nestas circunstâncias, a autoridade monetária pode e precisa intervir na dinâmica monetária, mas o faz por meio de "tateamento social" (De Brunhoff, 1973), como vimos anteriormente, o que impede o uso de regras pré-estabelecidas. É o caráter público hierarquicamente superior ao privado que dá à $\mathrm{Au}$ toridade Monetária a possibilidade de intervir na dinâmica monetária. A Autoridade Monetária não é, porém, onisciente, não tem a percepção correta do 
que ocorre na sociedade como um todo e nem das necessidades de moeda em cada setor, processo ou etapa. Assim, não pode controlar com precisão a dinâmica monetária. Isto mostra que a Autoridade Monetária encontra limites para o controle das dinâmicas monetárias porque seu caráter público não se confunde com o caráter social desta dinâmica. (De Brunhoff, 1982; Mollo, 1990)

Para os pós-keynesianos, o que impede as autoridades monetárias de controlar a dinâmica monetária perfeitamente é a incerteza que permeia a economia e a noção de tempo histórico ao analisar os processos econômicos e os efeitos das impulsões monetárias. A estrutura de produção vai se alterando ao longo das impulsões monetárias tornando irreversíveis as mudanças ocorridas nos curtos prazos. Assim, a Autoridade Monetária não pode intervir na dinâmica monetária a partir de regras, mesmo que flexíveis, porque as regras tornam-se logo inadequadas com as mudanças estruturais provocadas pelas impulsões monetárias. É preciso então um comportamento de sintonia fina que lhes permita perceber a cada momento as necessidades que vão se desenhando na economia, de forma a conduzir a política monetária adequadamente. Esta sintonia fina é mais importante ainda porque, conforme vimos, não é o papel do Banco Central de estabilizador de preços que é importante, porque para eles a moeda não é responsável pelo crescimento do nível geral de preços, mas é o de emprestador em última instância do Banco Central que importa. É este papel que evita ou aborta crises financeiras, e é o controle das taxas de juros em níveis baixos que garante a capacidade de investimento e crescimento econômicos.

Assim, tanto no caso dos marxistas quanto no dos pós-keynesianos, não é possível a chamada independência do Banco Central no sentido de impor como prioritário o controle monetário e a estabilidade de preços. A idéia, para os marxistas, é de que o Banco Central "tateia socialmente" entre os objetivos de garantir moeda suficiente para expandir a acumulação de capital e a necessidade de garantir o reconhecimento social da moeda como equivalente geral, reconhecimento que pode ser comprometido se o processo de emissão monetária por meio de sanção de dívidas privadas distorcer as relações credor-devedor ou sancionar preços e rendas sistematicamente divergentes dos valores criados e das rendas formadas na criação de valores. Este "tateamento social" só é possível se a sociedade como um todo manifestar demandas, o que não se faz com o Banco Central independente para cumprir objetivos de emissão monetária previamente definidos. Ao contrário dos ortodoxos, que querem ver o Banco Central protegido da ação dos políticos,${ }^{17}$ para os heterodoxos importa criar canais legítimos de pressão, de forma que o Banco Central apreenda a partir deles as necessidades monetárias da economia, podendo assim intervir de forma adequada sobre o crescimento e a evolução da atividade produtiva real.

${ }^{17}$ Ver em particular a posição de Kydland \& Prescott (1977) mencionada anteriormente. 
Também não é possível tal Banco Central independente na concepção póskeynesiana, já que em vista da incerteza é preciso deixar que os fatos e processos vão se explicitando, tornando as necessidades de liquidez aparentes. Trata-se de um processo de sintonia fina incompatível com a noção do Banco Central para cumprir uma regra de criação monetária ou atingir metas de inflação pré-determinadas.

As conclusões acima nos conduzem a uma outra: a de que as concepções monetárias heterodoxas em geral conduzem, como era de se esperar, a conclusões de operacionalização da política monetária inteiramente distintas. Mesmo no caso da concepção marxista, que percebe efeitos monetários sobre o nível de preços, esta conclusão se aplica, o que é uma outra forma de diferenciar ortodoxia e heterodoxia em matéria monetária.

\section{REFERÊNCIAS BIBLIOGRÁFICAS}

AGLIETTA, M. (1979) A Theory of Capitalist Regulation: The US Experience. London: Verso. (1976) “Monnaie et inflation: quelques leçons de l'expérience américaine des dix dernières années”. Économie et Statistique, n ${ }^{\circ} 77$, avril.

AKERLOF, G. A. \& Yellen, J. L. (1985) "A near-Rational Model of the Business Cycle with Wage and Prece Inertia”. Quarterly Journal of Economics, vol. 100, Supplement, pp. 823-838.

ALESINA, A. \& TABELLINI, G. (1987) "Rules and Discretion with Noncoordinated Monetary and Fiscal Policies”. Economic Inquiry, vol. XXV, $\mathrm{n}^{\circ} 4$, October.

ALESINA, A. \& SUMMERS, L. H. (1993) "Central Bank Independence and Macroeconomic Performance". Journal of Money, Credit and Banking, May.

ANDRADE, J. P., MOLLO, M. L. R. E SILVA, M. L. F. (1998) “Os Programas de Estabilização na América Latina: traços ortodoxos e heterodoxos”. Revista da Sociedade Brasileira de Economia Política, vol. 2, junho.

BLANCHARD, O. \& FISCHER, S. (1996) Lectures on Macroeconomics, Cambridge: MIT Press. BARRO, R. J. \& FISHER, S. (1976) "Recent Developments in Monetary Theory”. Journal of Monetary Economics, 2, pp. 133-167.

BARRO, R. J. \& GORDON, D. B. (1983) “A Positive Theory of Monetary Policy in a Natural Rate Model”. Journal of Political Economy, vol. 91, $\mathrm{n}^{\circ} 4$, august.

BLANCHARD, O. \& KIYOTAKI, N. (1987) "Monopolistic Competition and the Effects of Aggregate Demand”. American Economic Review, vol. 77, September, pp. 647-666.

CAGAN, P. (1989) Monetarism. The New Palgrave: A Dictionary of Economics. London and Basingstoke: The Macmillan Press Limited.

DAVIDSON, P. (1991) Controversies in Post Keynesian Economics. Aldershot-UK/Vermont-USA: Edward Elgar.

DE BRUNHOFF, S. (1988) État et Capital. Paris: Maspéro.

(1974) Les Rapports d'Argent. Grenoble: Presses Universitaires de Grenoble/François Maspéro.

(1973) La Politique Monétaire - um essai d'interprétation marxiste. Paris: Presses Universitaires de France.

DE BRUNHOFF, S. de \& CARTELIER, J. (1974) “Une Analyse Marxiste de l'Inflation”. Critique Sociale de France, 4.

DE VROEY, M. (1984) “Inflation: A Non-Monetarist Monetary Interpretation”. Cambridge Journal of Economics 8, pp. 381-399.

FISHER, I. (1930) The Rate of Interest. New York: Kelley. 
FOLEY, D. (1986) Money Accumulation and Crisis. Chur, London, Paris, New York: Harwood Academic Publishers.

FRIEDMAN, M. (1956) The Quantity Theory of Money: A Restatement, Studies in the Quantity Theory of Money. Chicago, IL: University of Chicago Press.

(1989) Quantity Theory of Money, The New Palgrave: A Dictionary of Economics. London and Basingstoke: The Macmillan Press Limited.

(1971) “An Independent Central Bank”, in: Monetary Economics Controversies in Theory and Policy. Toronto: J. Prager.

FRIEDMAN, M. \& SCHWARTZ, A. (1963) A Monetary History of the United States, 1897-1960. National Bureau of Economic Research, New York, Columbia University Press. GOODFRIEND, M. \& KING, R. G. (1997) The New Neoclassical Synthesis and the Role of Monetary

Policy. 1997 NBER Macroeconomics Annual.

HALL, R. E. (1983) “Optimal Fiduciary Monetary Systems”. Journal of Monetary Economics, 12, pp. 33-50.

HUME, D. (1752; 1963) Of Money. Essays Moral, Political and Literary. Oxford: Oxford University Press.

KALDOR, N. (1986). The Scourge of Monetarism. Oxford: Oxford University Press.

KEYNES, J. M. (1983) The Collected Writings of John Maynard Keynes. London: Macmillan and Cambridge University Press.

KYDLAND, F. E. \& PRESCOT, E. C. (1977) "Rules rather than Discretion: The Inconsistency of Optimal Plans". Journal of Political Economy, vol. 85, $\mathrm{n}^{\circ}$ 3, June.

LAIDLER, D. E. W. (1990) Taking Money Seriously and Other Essays. London: Philip Allan.

LIMA, G. T. SICSÚ, J. E DE PAULA, L. F. R. (1999). Macroeconomia Moderna - Keynes e a Economia Contemporânea. Rio de Janeiro: Campus.

LIPIETZ, A. (1983) Le Monde Enchanté: De la Valeur à L'Envol Inflationniste. Paris: La Découverte. MANKIW, N. G. (1985) “Small Menu Costs and Large Business Cycles: A Macroeconomic Model of Monopoly”. Quarterly Journal of Economics, vol. 100, May, pp. 529-537.

(1990) “A Quick Refresher Course in Macroeconomics". Journal of Economic Literature, vol. XXVIII, (december).

(2002) "The Inexorable and Mysterious Tradeoff between Inflation and Unemployment". Paper prepared as the Harry Johnson Lecture at The Annual Meeting of the Royal Economic Society, July.

MARX, K. (1971) O Capital. Rio de Janeiro: Civilização Brasileira.

(1974) O Capital, vol. III. Rio de Janeiro: Civilização Brasileira.

(1976) Théories sur la Plus Value. Paris: Les Editions Sociales

MINSKY, H. (1982) Inflation, Recession and Economic Policy. Armonk, New York: M. E. Sharpe. MOLLO, M. L. R. (1999) “The Endogeneity of Money: Marxian and Post-Keynesian Concepts Compared". Research in Political Economy, 18.

(1991) “A relação entre moeda e valor em Marx”. Revista de Economia Política, vol. 11, n 2, abr/jun.

(1993) “A Questão da Complementaridade das Funções da Moeda: aspectos teóricos e a realidade das hiperinflações”. Ensaios FEE, ano 14, n 1 , Porto Alegre.

(1994) “As Controvérsias Monetárias do Século XIX: traços ortodoxos e heterodoxos”. Ensaios FEE, vol. 29, ano 15, $\mathrm{n}^{\circ} 1$.

(1989) Monnaie, Valeur et Capital Fictif. Thèse de Doctorat. Paris: Université de Paris X.

(1988) "Instabilidade do Capitalismo, Incerteza e o Papel das Autoridades Monetárias: uma leitura de Minsky". Revista de Economia Política, vol. 8, n 1, jan/mar.

MOLLO, M. L. R. E SAAD FILHO, A. (2001) "Reconhecimento Social da Moeda:Observações sobre a Inflação e a Estabilização de Preços no Brasil”. Revista de Economia Política, vol. 21, n 2, abr/ jun.

MOLLO, M. L. R., SILVA, M. L. F. E TORRANCE, T. (2001) “Money and Exchange Rate: theoretical controversies”. Revista de Economia Contemporânea, vol. 5, n 1, janeiro-junho. 
MOORE, B. (1988) Horizontalists and Verticalists: The Macroeconomics of Credit Money. Cambridge: Cambridge University Press.

NEUMAYER, P. (1998) "Currencies and the Allocation of Risk: The Welfare Effect of a Monetary Union".

The American Economic Review, vol. 88, $\mathrm{n}^{\circ} 1$.

PATINKIN, D. (1956/1965) Money Interest and Prices. New York, Harper and Row. (1989) Neutrality of Money. The New Palgrave: A Dictionary of Economics. London and Basingstoke: The Macmillan Press Limited.

PIGOU, A. C. (1917) “The Value of Money”. Quarterly Journal of Economics, 17.

RICARDO, D. (1817/1982). Princípios de Economia Política e Tributação. São Paulo: Abril Cultural. ROTEMBERG, J. (1982) "Monopolistic Price Adjustment and Aggregate Output". Review of Economic Studies, vol. 44, p. 517-531.

ROUSSEAS, S. (1986) Post Keynesian Monetary Economics. London: Macmillan.

STUDART, R. (1999) “O Sistema Financeiro e o Financiamento do Crescimento”, in: Lima, Sicsú e de Paula (1999).

SAAD F', A. \& MOLLO, M. L. R. (2002) "Inflation and Stabilization in Brazil: A Political Economy Analysis". Review of Radical Political Economy, vol. 34, n ${ }^{\circ} 2$.

SHAIKH, A. M. (1999) "Explaining Inflation and Unemployment: An Alternative to Neoliberal Economic Theory", in: Andriana Vlachou (Ed.), Contemporary Economic Theory - Radical Critiques of Neoliberalism. London and New York: Macmillan Press and St. Martin Press.

SICSÚ, J. (2003) "Políticas Não-Monetárias de Controle da Inflação: uma proposta pós-keynesiana". Análise Econômica, ano 21, $\mathrm{n}^{\circ} 39$.

SMITHIN, J. (1994) Controversies in Monetary Economics — Ideas, Issues and Policy. Hants: Edward Elgar.

THORNTON, H. (1802/1962) An Inquiry into the Nature and Effect of the Paper Credit of Great Britain. Edited by F. A. von Hayek, New York: Augustus M. Kelley.

WICKSELL, K. (1906) Lectures on Political Economy. Londres: Routledge and Kegan Paul. VINER, J. (1937) Studies in the Theory of International Trade. New York: A. M. Kelley. 